Check for updates

Bain \& Company, London, UK

2 UK Parliament, London, UK

3 Birmingham Women's and Children's NHS Foundation Trust, Birmingham, UK

Correspondence to: J Marlow jeremy.marlow@bain.com

Cite this as: BMJ 2020;371:m3867 http://dx.doi.org/10.1136/bmj.m3867 Published: 27 October 2020

\title{
ESSAY
}

\section{Learning from a pandemic: how the post-covid NHS can reach its full potential}

\section{Out of the tragedy of the pandemic, there is a unique opportunity to accelerate reform in the NHS and prepare for a world living with and after covid-19, write Jeremy Marlow and colleagues} Jeremy Marlow, ${ }^{1}$ James O'Shaughnessy, ${ }^{2}$ Bruce Keogh, ${ }^{3}$ Nitin Chaturvedi ${ }^{1}$

The scale and degree of adaptation that the NHS has achieved in the past six months is unprecedented in its 72 year history. The service acted swiftly to bolster its emergency preparedness and resilience and rose to the challenge with innovation, energy, and kindness. But the pandemic has exposed its fragilities.

Questions are arising about how the NHS should plan for the future as well as capture and codify the experience of achieving change in such a fast, agile, and adaptive way. ${ }^{1}$ We think that there are three main areas of focus for planning a strategy:

- 1. Health and care delivery model redesign, including the integration and specialisation of services.

- 2. A more agile, fluid, multidisciplinary workforce, affecting staffing, training, and leadership requirements.

- 3. Greater ambition in the NHS on digitalisation, innovation, research and development, and public-private-academic partnerships.

The challenge to practitioners and policy makers alike is to build a consensus about the best practices emerging from the covid-19 response and then to execute a strategy designed to make them a permanent feature of a new NHS model.

\section{Control versus empower}

At the peak of the pandemic in the UK, command was centralised with gold (strategic oversight for escalating major issues and resource redeployment decisions) and silver (local tactical coordination of responders for rapid problem solving and support) centres following the NHS's emergency response framework and in England working closely with the 42 sustainability and transformation plan partners. The extent to which local NHS providers accepted pooling their sovereignty to more collective decision making was varied. It was most effective in some regions and integrated care systems. The role and direction of the NHS London team, for example, has been a major help in coordinating efforts in the capital. But this is a short term model that can only exist in extreme circumstances. The NHS needs to find a steady state that allows rapid, local decision making. Continuing reliance on national command structures is dangerous and will cause atrophy and disempower good organisations.
Nothing shows the urgent need for integration like the effects of covid-19 on the social care sector. ${ }^{2}$ Some aspects of the response have shown how well integrated health and social care can perform together. Collaboration to ensure that medically fit patients were transferred out of hospital to home or to step-down care meant that hospitals were able to generate surge capacity and not be overwhelmed. ${ }^{3}$ Technology enabled the rapid deployment of carers to achieve 10 ooo home visits a day and helped relatives to maintain contact. ${ }^{4}$ Providers worked with the government to create a platform for recruiting people from other sectors, vetting them online, providing virtual training, and matching to roles to reduce shortages and provide employment. ${ }^{5}$ But the absence of any national infrastructure around the fragmented market of social care providers meant the reciprocal support for them was impossible to achieve in the same way that it was for the NHS.

The absence of coordinated surge support for social care has shown how much needs to be done to attend to fragility in the sector. This gives NHS institutions (such as hospital trusts and primary care networks) the opportunity to work alongside local authorities to act as "anchor organisations" to support social care providers in clinical and infection prevention and control protocols; staff development; data sharing and reporting; and introducing new (digital) technologies.

The sector has been exposed as isolated and precarious, with many providers teetering on the brink of insolvency. The energy of its leaders is focused on staff and residents, but the tragedy of covid-19's impact on social care must be a tipping point for a consensus on a longer term settlement for social care and new models of provision.

\section{Courage and conviction}

The culture of frontline NHS organisations has undoubtedly been tested in the response to covid-19. In many cases, people's resilience and motivation have strengthened through a visceral realisation of sense of purpose and urgency. There are many stories of frontline staff telling their loved ones that they might never see them again and the tragic situations where those fears have been realised. Values of selflessness, care for colleagues, creativity, and kindness have shone through.

Beyond this courage, new behaviours emerged. Multidisciplinary working flourished, such as 
surgeons working in intensive care and being excited to be part of the team. The consistency this has given to ward rounds has recaptured the strengths of the old "firm" apprentice model of medical training. Rotas have changed quickly with minimal bureaucracy, putting the interest of the whole system first. An insurgent positive mindset has been the biggest driver of innovation, pace, and common purpose, with eagerness to try new things and the relegation of professional and institutional silos.

Several "field innovations" came from the necessity to achieve best possible outcomes in an unprecedented situation. The clinical, social, and economic benefits of integrating rehabilitation early into the recovery of patients were shown through the rapid development of step-down units for patients in intensive care at Nottingham University Hospitals. Cross discipline clinicians were able to write new protocols and agree new admissions criteria at speed, dramatically changing the way inpatients were treated (Miriam Duffy, personal communication, 2020). During tracheostomy clinicians were able to help patients communicate by enabling the use of speaking valves on their tracheostomy, where appropriate, and by encouraging oral intake as soon as it was safe to do so. These procedures were usually not used outside of Nottingham University Hospital's therapy led units or in such a high profile environment owing to the perceived risk.

This agility of leadership has accelerated change that previously required time consuming consultative machinery, layers of approvals, and autocratic decision making in small cliques. NHS leaders must now reflect and choose which archetype and style of leadership gives them the best opportunity for achieving the greatest results.

\section{Innovation and ambition}

Over the next two years health and care systems will need to experiment and embed new models. We need to plan to live with covid-19 and for life after it. Which innovations do we want to keep, and can they have dual use for treating other diseases? This will be especially important now that infectious disease will be re-established as a major health risk. What lessons can we draw from the covid-19 response to reduce the 10 ooo deaths per year from seasonal flu ${ }^{6}$ ?

As the NHS and life sciences improve their understanding and practices in response to covid-19, the biggest risk to public satisfaction is the effect covid-19 has had on all the other demands for health and social care services. The longer it takes for the NHS to recover the backlog of unmet demand the more harm will be caused. The number of people being referred for consultant led elective treatment reduced by $69 \%$ from pre-covid levels of 1.6 million in February this year to a low point of 0.5 million in April and recovered to 1.1 million by August. Meanwhile, the number of people waiting over one year for treatment has increased at a scale not seen since data started to be collected over a decade ago. In February this year 1600 people were waiting over a year. This number has increased every month since then and by August had grown by $6783 \%$ to over 110 ooo-a level not seen since $2008 .^{7}$

Solutions to many of these challenges are at hand. Digital communications and technologies are being embraced at a scale never dreamt of in the NHS $-99 \%$ of general practices ${ }^{8}$ are now capable of delivering care virtually. The triaging of symptoms has been streamlined with technology, with more outpatient consultations being delivered away from hospital settings. ${ }^{9}$ Home and personal remote monitoring is being tested for use in the whole population. As the pressures subside, the temptation to revert to the status quo will grow. The expectation should be that most outpatient and follow-up appointments will be virtual by default.

The poor level of understanding of covid-19 has driven an upsurge in research and development activity in the NHS and in conjunction with universities and private companies, including vaccine development (such as the partnership between Oxford and AstraZeneca ${ }^{10}$ and the NHS Lighthouse Laboratories with Thermo Fisher) and the rapid trialling of therapeutics. ${ }^{11}$ Bearing in mind the government's determination to increase the UK's investment in research and development to $2.4 \%$ of gross domestic product by 2027, the NHS has shown that it can be a superb platform for translational research and later stage development, complementing our world class science base. This is a golden opportunity to build on. The key questions are how a broader base of institutions can contribute to the effort, as they have in other countries, and how established structures, such as the academic health science networks, can further mobilise to maintain the momentum of academic, private, and hospital collaboration that the pandemic response has generated.

\section{Aiming for full potential}

The general scientific consensus is that we will not have a deployable covid-19 vaccine or treatment until 2021. We might never have a completely effective vaccine, and covid-19 will become an endemic disease with seasonal spikes, or it might suddenly disappear. So much is unknown, but for the time being we need to prepare for a prolonged era of living with covid-19. Continuing the momentum of recent innovation and productivity gains will be vital if health and care services are to return to their previous operating capacity and ultimately their full potential.

The demands on leadership are unprecedented, requiring a combination of strategic, tactical, and soft skills. Leadership and decision making responsibilities will have to be more vertically distributed and preserve the "servant leader" mindset of the initial pandemic response, which has shown that anyone can display leadership regardless of their position. As well as showing a different kind of leadership, the crisis response has smashed longstanding barriers between different health and care settings and functions. For those concerned by the fragmentation of services, this might be considered the greatest gain of all. We now have an opportunity to redesign services around user journeys rather than top-down reorganisations or institutional fiefdoms. We need to be more agile and flexible, have more resilience with fewer single points of failure, and harness the understanding of what motivates the frontline and engages the public. Disempowering local leaders in the task of deciding how best to resume services will lose the goodwill and momentum of the past six months and make systems more fragile.

Meanwhile the flourishing of covid-19 related research activity in NHS settings has revealed two important truths. First, there is a huge appetite for research activity among clinical staff if enough time and suitable structures can be found. And second, the suitability and attractiveness of the NHS as a platform for medical research and development once the cultural and financial barriers to partnership with the private sector are lowered.

As difficult as the past six months have been, this period might turn out to be the easiest of many phases that await us. We need adaptable plans that maintain a constant state of readiness. If this can be achieved, the NHS and care systems will come out strengthened and revered, not just as providers of exemplary healthcare but as drivers of economic recovery and wealth creators for the nation. 


\section{Biographies}

Jeremy Marlow is a senior adviser at Bain \& Company and until 2018 was the executive director of operational productivity at NHS Improvement. Before that he was a civil servant in the UK government serving in senior roles in the Department of Health and Social Care, Department for Environment, Food, and Rural Affairs, HM Treasury, and the Cabinet Office. James O'Shaughnessy served as the parliamentary undersecretary of state at the Department of Health and Social Care between 2016 and 2018. He was made a life peer in 2015. Between 2007 and 2011 he was director of policy for David Cameron. He is currently an adviser to Bain \& Company.

Bruce Keogh served as England's national medical director from 2007 to 2017. Before that, he was a cardiac surgeon. He currently serves as the chair of Birmingham Women's and Children's NHS Foundation Trust and is an adviser to Bain \& Company.

Nitin Chaturvedi is a partner based in Bain \& Company's London office. He leads the firm's UK healthcare practice with more than 20 years of consulting experience across healthcare including biopharma, medtech, and providers across the world.

Competing interests: All authors have read the competing interest statement

(https://bmj.com/cgi/content/full/317/7154/291/DC1) and declare that the answer to the questions are all No except for Question 1, part vi and Question 2 which are answered Yes. All authors have accepted fees for consulting. JM and NC are employees of Bain \& Company providing consulting services to NHS organisations, and JOS and BK are advisers to Bain \& Company. This manuscript was born out of a discussion between current and former senior NHS personnel which was convened by Bain \& Company, a global consultancy.

We acknowledge the following for their contributions and feedback in the development of this essay subsequent to a roundtable discussion in April 2020: David Behan, David Dalton, Noel Gordon, Jim Mackey, Mahiben Maruthappu, lan Peters, and Miriam Duffy.

1 Edwards N. Here to stay? How the NHS will have to learn to live with coronavirus. Nuffield Trust. 2020 https://www.nuffieldtrust.org.uk/files/2020-06/1591362811_nuffield-trust-here-to-stayhow-the-nhs-will-have-to-learn-to-live-with-coronavirus.pdf.

2 Care Quality Commission. Sharing insight, asking questions, encouraging collaboration: CQC publishes first insight document on covid-19 pressures. 2020

https://www.cqc.org.uk/news/stories/sharing-insight-asking-questions-encouraging-collaborationcqc-publishes-first-insight-document-on-covid-19-pressures.

3 NHS England and NHS Improvement. Important and urgent-next steps on NHS response to covid-19. 17 Mar 2020. https://www.england.nhs.uk/coronavirus/wp-content/uploads/sites/52/2020/03/20200317-NHS-COVID-letter-FINAL.pdf

4 Exclusive CS. Cera plans to roll out assistive technology this year. Home Care Insight. $21 \mathrm{Apr}$ 2020. https://www.homecareinsight.co.uk/exclusive-cera-plans-assistive-technology-roll-outthis-year/

5 Department of Health and Social Care. Register here to become a care worker and help change lives. https://www.joinsocialcare.co.uk/

6 Hardelid P, Pebody R, Andrews N. Mortality caused by influenza and respiratory syncytial virus by age group in England and Wales 1999-2010. Influenza Other Respir Viruses 2013;7:35-45. doi: 10.1111/j.1750-2659.2012.00345.x pmid: 22405488

7 NHS England. Consultant-led referral to treatment waiting times. https://www.england.nhs.uk/statistics/statistical-work-areas/rtt-waiting-times/

8 Bakhai $\mathrm{M}$. The use of online and video consultations during the covid-19 pandemic - delivering the best care to patients. NHSX. 2020 https://www.nhsX.nhs.uk/blogs/use-online-and-videoconsultations-during-covid-19-pandemic-delivering-best-care-patients/.

9 Schwamm LH, Estrada J, Erskine A, Licurse A. Virtual care: new models of caring for our patients and workforce. Lancet Digit Health 2020;2:e282-5.

doi: 10.1016/S2589-7500(20)30104-7 pmid: 32382724

10 University of Oxford. Oxford University announces landmark partnership with AstraZeneca for the development and potential large-scale distribution of COVID-19 vaccine candidate. 2020. https://www.ox.ac.uk/news/2020-04-30-oxford-university-announces-landmark-partnershipastrazeneca-development-and.

11 UK Bioindustry Association. Health Secretary pays tribute to UK life sciences companies, as testing ramps up for covid-19. 2020. https://www.bioindustry.org/news-listing/health-secretarypays-tribute-to-uk-life-sciences-companies-as-testing-ramps-up-for-covid-19.html.

This article is made freely available for use in accordance with BMJ's website terms and conditions for the duration of the covid-19 pandemic or until otherwise determined by BMJ. You may use, download and print the article for any lawful, non-commercial purpose (including text and data mining) provided that all copyright notices and trade marks are retained. 